\title{
Disability and Invisibility in STEM Education
}

\author{
Joseph Schneiderwind \\ Metropolitan State University of Denver \\ Janelle M. Johnson \\ Metropolitan State University of Denver
}

\begin{abstract}
Across STEM fields, the education system continues to "weed out" students from non-dominant communities. Most studies on the damaging effects of underrepresentation focus on minorities or women in STEM fields. We examine some of the research about students with disabilities and note the limited literature on this subject. University enrollment by students with disabilities has increased in the last two decades while the amount of corresponding research published has decreased. This issue should not be siloed to disability studies- it is one that must be recognized by all educators. We conclude with some practical suggestions on how to move forward.
\end{abstract}

Keywords: disability, STEM, equity, inclusion, disproportionality, tracking, differentiation

\section{INTRODUCTION}

In the United States we lament the lack of diversity in STEM fields and in teacher education, but many of our actions as educators continue to "weed out" students from non-dominant communities and those who are differently abled. Society, parents, and other students need to understand that students with disabilities are as capable of academic achievement as any other student given the proper accommodations that allow for success. This is an issue that should not be limited to the silo of disability studies-it is one that must be recognized by all educators.

\section{Academic Tracking of Students With Disabilities}

Students with disabilities are less likely to complete high school than other students, but why? There are certainly many social and societal factors that serve as barriers, but school and classroom practices are contributing factors as well. Elementary students with disabilities tend to be tracked away from pursuing advanced academic endeavors. These students are systematically "hidden" from general education and forced into separate classrooms, different programs, and alternative schools. School funding formulas based on standardized assessments incentivize schools to do just that since students with disabilities tend to receive lower scores on these high-pressure exams (Thurlow et al., 2002).

Recent research has shown that $10 \%$ of students entering postsecondary education have some type of self-identified disability (US Department of Education, 2009), but there is stark disproportionality of students with disabilities enrolled in advanced coursework in high school. In secondary education, few students with disabilities take AP or IB or enroll in STEM classes or programs. Students with disabilities account for 
about $12 \%$ of the student population in secondary school, but only $1 \%$ of the students in advanced placement courses (Office for Civil Rights, 2014). Further illustrating the disparities apparent in STEM fields, high school students with disabilities acquire approximately the same number of credits in English as other students, but far fewer credits in math or science (Newman, 2011). This underrepresentation can lead people to assume that students with disabilities are less capable, particularly in STEM-related fields, and the students themselves may begin to believe they are less qualified, feeding a cycle of low expectations and underperformance.

\section{An Invisible but Growing Problem}

Research shows the impact of social upbringing, the media, and self-reinforcement on students who are statistically not "supposed" to do well - they tend not to, and this is referred to as the expectancy effect. The expectancy effect leads to lower test performance, less interest in pursuing studies in science and mathematics, and reduced effort to pursue counter-stereotypic skills, amongst other things. Most studies on expectancy effect focus on racial and ethnic minorities or women in STEM fields (Scott, 2014), but it is logical to assume the same damaging effect on students with disabilities. Peña (2014) performed a thorough search of peer-reviewed articles published in four of the top academic journals. It was found that only $1 \%$ of published work in these journals had to do with disabilities; and, while published work on students with disabilities has decreased in the last two decades, admissions of students with disabilities have increased. Recognition of an issue in academia tends to be reflected in the amount of published works on the subject, and this poses a serious concern in recognizing the difficulties that these students will endure. Further, research on students with disabilities tends to group them as a whole rather than separating them into those with intellectual or learning disabilities and those with other disabilities, which can have significant effects on the outcomes of research as it pertains to education (Vaccaro, 2015).

When we began working on this article, we realized the research literature on this area was extremely thin. One helpful 2012 publication is titled "Accommodating students with Disabilities in Science, Technology, Engineering, and Mathematics (STEM)." The authors write that "teachers, instructors, and professors are frequently unable, unprepared, or otherwise ill-equipped to recognize and address the needs of students with disabilities. As a result, course content may be inaccessible" (Moon et al., 2012; p. 12). If students cannot access opportunities that feed into a STEM pipeline, they are essentially invisible. Students with disabilities therefore remain underrepresented in STEM fields, and a need exists to help uncover barriers that students with disabilities encounter in STEM laboratories, for example (Jeannis, 2018). One out of 10 students in postsecondary education identify as having a disability (US Department of Education, 2009), and we know many other students who do not report having a disability because of the stigma it carries. The combination of the lack of accurate numbers of students with disabilities and the overall invisibility of this issue make it urgent to address.

\section{Blind Spots in Teaching and Teacher Education}

Federal policies that recognize the rights of students with disabilities were an important step, and meant teachers could not legally ignore these students. But many educators don't seem to fully understand what students with disabilities need. While there are educators who do specialize in working with exceptional learners, training for teachers who do not work in special education can be limited. Tools and approaches like Universal Design for Learning are helpful in supporting differentiation in order to help all students. But they do not necessarily help classroom teachers recognize their own potential bias about the ability of students with disabilities that lower their expectations of students' academic potential.

And what about teachers who have disabilities? Section 504 of the Rehabilitation Act and the ADA pertains to both students and teachers; students have the additional support of education acts like the Individuals with Disabilities Education Act (IDEA). Employees are protected by Section 504 and the ADA so long as they can perform essential functions, but how well do these policies actually support teachers who have disabilities? If we consider that only $35 \%$ of individuals with disabilities who are qualified for a position are actually employed (Bonnaccio, 2020), the lack of specific resources pertaining to teachers with disabilities is troubling. 


\section{CONCLUSION}

Important societal transformation is happening with growing awareness of racism, and seeking out actions we can take to change the equation. Individuals with disabilities also suffer the effects of discrimination, and there are actions we can and must take to dismantle the systemic barriers to educational opportunity for all our students. Principals can actively recruit teachers with disabilities and let them know they are welcome and will be supported in the workplace (Also see Pope, Bowman \& Barr (2001) for specific recommendations). Prior to implementing anything new or different, teachers can ask students with disabilities what they think would be helpful or what has been helpful in the past. This would help prevent falling into the same trap of promoting what the teachers think would be helpful without quantitative or qualitative data to support these accommodations. In this age of technology, there are many available tools to assist students with disabilities. Referring more specifically to physical disabilities, make sure to learn about and provide students and families access to technology programs and related hardware such as Dragon NaturallySpeaking, MathTalk, Vocola, Equatio, and Google Speech to Text, all of which allow for access to what able-bodied students take for granted - the beauty and simplicity of paper and pencil.

Joe Schneiderwind is a future math teacher who was a student in Dr. Janelle Johnson's Multicultural Education class. Students had to choose an issue they were passionate about to research and share a "Call to Action" with their classmates. Joe's reflection on his own educational experiences led him to research the underrepresentation of students with disabilities in STEM fields. He was diagnosed with multiple sclerosis in 2005. He graduated with a BS in Engineering Physics in 2009 and an MS in Applied Mathematics in 2011. By 2014 he was heavily dependent on a wheelchair. After leaving a PhD program due to further progression of his disability, he is now attending Metropolitan State University of Denver seeking licensure to teach secondary mathematics.

Dr. Janelle Johnson is an Associate Professor of STEM Education at Metropolitan State University of Denver. She is the co-editor of STEM21: Equity in Teaching and Learning to Meet Global Challenges of Standards, Engagement, and Transformation (2018), and the Principal Investigator on two National Science Foundation grants - A Community-based Approach to Engaging Students and Teachers in Effective STEM Education ITEST grant, and Inclusive STEM Teaching Preparation at an Urban Commuter University (U-STEM) Robert Noyce grant. Her work focuses on professional development with teachers towards interdisciplinary and inclusive STEM teaching and learning. She taught Math and Earth Science courses to bilingual and ESL students in Guatemala and in Arizona for eight years at elementary, middle, and high school levels.

\section{ACKNOWLEDGEMENT}

A similar version to this article was previously published as Schneiderwind, J. \& Johnson, J.M. (2020, July 27). Why Are Students with Disabilities so Invisible in STEM Education? Education Week Teacher Letters.

\section{REFERENCES}

Bonaccio, S., Connelly, C.E., Gellatly, I.R., Jetha, A., \& Martin Ginis, K.A. (2020). The Participation of People with Disabilities in the Workplace Across the Employment Cycle: Employer Concerns and Research Evidence. Journal of Business Psychology, 35, 135-158

Jeannis, H., Joseph, J., Goldberg, M., Seelman, K., Schmeler, M., \& Cooper, R.A. (2018). Fullparticipation of students with physical disabilities in science and engineering laboratories. Disability and Rehabilitation: Assistive Technology, 13(2), 186-193.

Moon, N.W., Todd, R.L., Morton, D.L., \& Ivey, E. (2012). Accommodating students with disabilities in science, technology, engineering, and mathematics (STEM). Atlanta, GA: Center for Assistive Technology and Environmental Access, Georgia Institute of Technology, pp. 8-21. 
Newman, L., Wagner, M., Huang, T., Shaver, D., Knokey, A.M., Yu, J., ... Cameto, R. (2011). Secondary School Programs and Performance of Students with Disabilities: A Special Topic Report of Findings from the National Longitudinal Transition Study-2 (NLTS2). NCSER 20123000. National Center for Special Education Research.

Office for Civil Rights. (2014). Data Snapshot: College and Career Readiness. Retrieved from https://www2.ed.gov/about/offices/list/ocr/docs/crdc-college-and-career-readiness-snapshot.pdf

Peña, E.V. (2014). Marginalization of published scholarship on students with disabilities in higher education journals. Journal of College Student Development, 55(1), 30-40.

Pope, C., Bowman, C., \& Barr, K. (2001). Conversations from the Commissions: Negotiating the Tensions in the Preparation of Teachers with Disabilities. English Education, 33(3), 252-256. Retrieved June 4, 2020, from www.jstor.org/stable/40173070

Scott, A., \& Martin, A. (2014). Perceived barriers to higher education in science, technology, engineering, and mathematics. Journal of Women and Minorities in Science and Engineering, 20(3).

Thurlow, M.L., Sinclair, M.F., \& Johnson, D.R. (2002). Students with Disabilities Who Drop Out of School: Implications for Policy and Practice. Issue Brief: Examining Current Challenges in Secondary Education and Transition.

U.S. Department of Education, National Center for Education Statistics. (2009). 2003-04 and 2007-08 National Postsecondary Student Aid Study (NPSAS:04 and NPSAS:08). Retrieved from http://nces.ed.gov/programs/digest/d10/ tables/dt10_240.asp

Vaccaro, A., Kimball, E.W., Wells, R.S., \& Ostiguy, B.J. (2015). Researching students with disabilities: The importance of critical perspectives. New Directions for Institutional Research, 2014(163), $25-41$. 